\title{
CONSÓRCIO SORGO-SOJA. V. COMPORTAMENTO DE HÍBRIDOS DE SORGO E CULTIVARES DE SOJA CONSORCIADOS NA ENTRELINHA NO RENDIMENTO DE FORRAGEM
}

\author{
SORGHUM AND SOYBEAN INTERCROPPING. V. BEHAVIOR OF HYBRIDS OF SORGHUM AND \\ CULTIVARS SOYBEAN INTERCROPPED BETWEEN ROWS FORAGE YIELD
}

\section{Pedro Milanez de Rezende ${ }^{1}$ Alessandro Guerra da Silva ${ }^{2}$ Edivandro Corte $^{2}$ Élberis Pereira Botrel ${ }^{2}$}

RESUMO

Com o objetivo de verificar o comportamento de cultivares de sorgo e soja em cultivo consorciado e o sorgo em monocultivo na produção de forragens, foi conduzido, no ano agrícola 1996/97, um ensaio no Departamento de Agricultura no Campus da Universidade Federal de Lavras, em Lavras, MG, em um Latossolo Roxo Distrófico. $O$ delineamento experimental utilizado foi o de blocos casualizados em esquema fatorial $4 \times 4+4$ com três repetições, sendo constituído por quatro híbridos de sorgo forrageiro ( $A G$ 2002, AG 2006, BR 601 e CMSXS 756), quatro cultivares de soja (CAC-1, Doko RC, UFV-16 e UFV-17) e quatro tratamentos adicionais, correspondentes aos respectivos monocultivos de sorgo. Foi realizado apenas um corte, rente ao solo, no consórcio no estádio $R_{5}$ (início da formação das sementes da cultura da soja) e no monocultivo de sorgo, no estádio de grãos farináceos. Os resultados obtidos evidenciaram que a combinação da cultivar UFV-16 com os híbridos AG 2002 e AG 2006 proporcionou os maiores rendimentos de massa verde, matéria seca e proteína bruta total. No consórcio e em monocultivo, o híbrido AG 2002 foi o que mais se destacou para a produção de massa verde e matéria seca. Em geral, o sistema consorciado proporcionou, em relação ao monocultivo, os maiores rendimentos de massa verde, matéria seca e proteína bruta total.

Palavras-chave: matéria seca, monocultura, forragem

\section{SUMMARY}

With the purpose of evaluating the behavior of sorghum and soybean cultivars in intercropping for forage production and sorghum in monoculture, a trial was conducted in the agricultural year of 1996/1997 at the Department of Agriculture of the Universidade Federal de Lavras- MG, on a distrophic red dusky latosol. The experimental design was that of randomized blocks in a $4 \times 4+4$ factorial scheme, with three replications, being made up of four hybrids of forage sorghum (AG-2002, AG-2006, BR-601 and CMSXS-756), four soybean cultivars (CAC-1, Doko RC, UFV-16 and UFV-17) and four additional treatment corresponding to the respective monoculture of sorghum. In the intercropping, a single cutting chose to the soil surface at $R_{5}$ stage was performed (beginning of the set of the soybean crop seeds), in the sorghum monoculture the cut was done, with grains in mealy stage. The results obtained made it evident that the combination of the cultivar UFV-16 with the hybrids AG-2002 and AG-2006 were the ones which provided the greatest green mass, dry matter and total crude protein yields. Both in the consortium and monoculture, the hybrid AG-2002 was that which stood out the most for dry matter and green mass production. In general, the consortium system provided, in relation to monocultivation, the highest green mass,dry matter and total crude protein yields.

Key words: dry matter, monoculture, forage.

\section{INTRODUÇÃO}

O consórcio, prática muito utilizada nas propriedades agrícolas, encontra-se na dependência direta das culturas envolvidas, havendo a necessidade de uma complementação entre ambas para que esse sistema seja mais vantajoso em relação ao monocultivo. Em espécies como o milho e sorgo, a proteína é fator limitante para a produção de silagens, estando abaixo dos níveis exigidos pelos animais. Uma das alternativas que o pecuarista pode lançar mão para melhorar o valor nutritivo do alimento fornecido na época de escassez e diminuir os custos de suplementação protéica é a utilização de alimentos ricos em proteína, produzidos na própria fazenda. O uso da soja ensilada, juntamente com as gramíneas, tem-se destacado, pois a cultura, na maioria

\footnotetext{
${ }^{1}$ Engenheiro Agrônomo, Doutor, Professor Titular do Departamento de Agricultura da Universidade Federal de Lavras (UFLA), CP 37 , 37200-000. Lavras - MG (Bolsista do CNPq). Autor para correspondência.

${ }^{2}$ Engenheiro Agrônomo, Pós-graduando do Departamento de Agricultura - UFLA 
do casos, não diminui a produtividade forrageira da gramínea, aumenta o teor de proteína da silagem e proporciona ganhos de peso significativamente maiores (CARNEIRO \& RODRIGUEZ, 1980; MONTGOMERY, 1983; EVANGELISTA, 1986 e OLIVEIRA, 1986).

O cultivo consorciado do milho com a soja torna-se vantajoso quando o objetivo principal é a produção de forragens (OLIVEIRA, 1986). Por sua vez, HARBERS et al. (1992) observaram que o suprimento de silagem contendo sorgo e soja é uma ótima opção em substituição à silagem de milho, podendo se obter bons resultados no uso desses alimentos. Nesse contexto, a planta de soja aparece com destaque, pois pode fornecer forragem na forma de feno e/ou massa verde, conforme resultados obtidos por vários pesquisadores (CARNEIRO \& ROGRIGUEZ, 1978; REZENDE, 1984; CARDOSO, 1985; REZENDE \& TAKAHASHI, 1990 e REZENDE, 1995).

Dessa forma, este trabalho teve como objetivo verificar o comportamento de híbridos de sorgo e cultivares de soja, consorciados na entrelinha, quanto ao seu valor nutritivo e rendimento forrageiro, comparado ao rendimento forrageiro do sorgo em monocultivo.

\section{MATERIAL E MÉTODOS}

O ensaio foi instalado em Lavras - MG (latitude de $21^{\circ} 14^{\prime} \mathrm{S}$, longitude $45^{\circ} 00 \mathrm{~W}$ e altitude de 918m), no campo experimental do Departamento de Agricultura da Universidade Federal de Lavras UFLA, no ano agrícola 1996/97 em Latossolo Roxo distrófico, de textura argilosa, fase cerrado que apresentou os seguintes resultados: $\mathrm{pH}$ em água: $5.1, \mathrm{P}$ : $11 \mathrm{mg} / \mathrm{dm}^{3}, \mathrm{~K}: 58 \mathrm{mg} / \mathrm{dm} 3, \mathrm{Ca}: 2,8 \mathrm{cmolc} / \mathrm{dm} 3, \mathrm{Mg}$ : $0,9 \mathrm{cmo} \ell \mathrm{c} / \mathrm{dm}^{3}, \quad \mathrm{Al}: 0,2 \mathrm{cmo} \ell \mathrm{c}^{2} \mathrm{dm}^{3}, \mathrm{H}+\mathrm{Al} ;$ $5,0 \mathrm{cmo} \ell \mathrm{c} / \mathrm{dm}^{3}, \mathrm{~S}: 3,8 \mathrm{cmo} \ell \mathrm{c} / \mathrm{dm}^{3}, \mathrm{t}: 4,0 \mathrm{cmo} \ell \mathrm{c} / \mathrm{dm}^{3}$, T: $8,8 \mathrm{cmo} \ell \mathrm{c} / \mathrm{dm}^{3}, \mathrm{M}: 5 \%, \mathrm{~V}: 43 \%$, MAT.ORG: 3,1 dag $/ \mathrm{dm}^{3}$, AREIA: $30 \%$, LIMO: $26 \%$, ARGILA:44\%. As variações diárias da temperatura média e da distribuição de chuvas durante a condução do ensaio foram normais para as culturas não ocorrendo déficit hídrico.

A semeadura foi realizada em 23/10/96, utilizando-se materiais recomendados para o Estado, sendo quatro híbridos de sorgo forrageiro (AG 2002, AG 2006, BR 601 e CMSXS 756) consorciados na entrelinha com quatro cultivares de soja (CAC-1, Doko RC, UFV-16 e UFV-17), em todas as combinações possíveis. A época de corte foi determinada em função da cultura da soja, sendo que as plantas de ambas as espécies em consórcio foram cortadas rente ao solo, quando as plantas da leguminosa atin- giram o estádio $\mathrm{R}_{5}$ (início da formação das sementes) de acordo com FEHR \& CAVINESS (1977).

$\mathrm{O}$ delineamento experimental empregado foi o de blocos casualizados, com três repetições, em esquema fatorial $4 \times 4 \times 4$ constituído pelos quatro híbridos de sorgo e das quatro cultivares de soja, acrescido dos quatro híbridos em monocultivo. Paralelamente, foi conduzido outro ensaio contíguo em blocos casualizados com três repetições para o monocultivo de sorgo, sendo o mesmo cortado, rente ao solo, no estádio de grãos farináceos que, segundo FARIA (1986), representa a melhor época para efetuar a ensilagem da cultura.

Tanto no monocultivo como no consórcio, as parcelas de sorgo foram constituídas por três linhas espaçadas de $0,8 \mathrm{~m}$ com 5,0m de comprimento, considerando como área útil a fileira central $\left(4,0 \mathrm{~m}^{2}\right)$, atendendo o mínimo exigido para a cultura da soja, $2,0 \mathrm{~m}^{2}$. Para a cultura da soja, foi utilizado o sistema de consórcio na entrelinha do sorgo, utilizando também uma linha como área útil. O desbaste foi realizado aos 25 dias após a emergência das plântulas, procurando-se manter 12 plantas por metro linear para o sorgo no consórcio e monocultivo, e 24 plantas por metro linear para a soja.

Para ambas as culturas, a calagem e a adubação seguiram as recomendações feitas pela COMISSÃO DE FERTILIDADE DO SOLO DO ESTADO DE MINAS GERAIS (1989). Sessenta dias antes de efetuar a semeadura, aplicou-se o equivalente a 2,4t de calcário calcítico/há, utilizando-se o método de saturação de bases, $\mathrm{V}=60 \%$. Antes da semeadura, foi feita a inoculação das sementes de soja com Bradyrhizobium japonicum, utilizando inoculante turfoso, na proporção de $200 \mathrm{~g}$ de inoculante para $40 \mathrm{~kg}$ de sementes.

Para a cultura do sorgo, tanto em consórcio como em monocultivo, empregou-se, por ocasião da semeadura, o equivalente em $\mathrm{kg} / \mathrm{ha}$ a 20 de $\mathrm{N}$, 120 de $\mathrm{P}_{2} \mathrm{O}_{5}$ e 120 de $\mathrm{K}_{2} \mathrm{O}$, sendo realizados aos $30 \mathrm{e}$ 45 dias após a emergência das plantas de sorgo, cobertura $60 \mathrm{~kg}$ de N/ha. Para a cultura da soja, em consórcio, aplicou-se, por ocasião da semeadura, o correspondente a $80 \mathrm{~kg}$ de $\mathrm{P}_{2} \mathrm{O}_{5}$ e $40 \mathrm{~kg}$ de $\mathrm{K}_{2} \mathrm{O} / \mathrm{ha}$. Todos os tratamentos receberam, sempre que necessário, os tratos culturais para ambas as culturas.

O corte das plantas foi realizado com roçadeira costal motorizada nas épocas já relatadas anteriormente. Os materiais foram determinados separadamente, a fim de se obterem dados de contribuição de cada cultura individualmente. Posteriormente, somaram-se os rendimentos do sorgo e soja, sendo analisados os rendimentos de massa verde total $(\mathrm{kg} / \mathrm{ha})$, de matéria seca total (determinado a partir de amostra de $200 \mathrm{~g}$ de massa verde em estufa 
a $65^{\circ} \mathrm{C}$ até peso constante e convertido em $\mathrm{kg} / \mathrm{ha}$ ) e de proteína bruta total utilizando a mesma amostra usada na determinação da matéria seca, utilizando-se o método Kjeldahl e transformado, posteriormente, os dados para $\mathrm{kg} / \mathrm{ha}$.

Foram realizadas análises estatísticas combinadas (consórcio + monocultivo) para as características citadas anteriormente, utilizando-se o somatório das duas culturas (sorgo + soja). Para diferenciação das médias, entre consórcio x monocultivo foi aplicado o teste de $\mathrm{F}$, e para as médias das cultivares de soja $\mathrm{x}$ sorgo, híbridos de sorgo $\mathrm{x}$ soja e monocultivo do sorgo foi aplicado o teste de Duncan. Os resultados obtidos para o consórcio foram comparados com os respectivos monocultivos de sorgo, através do teste " $t$ " de contraste. O nível de significância utilizado para as análises foi de $5 \%$.

\section{RESULTADOS E DISCUSSÃO}

\section{Rendimento de massa verde (MVT) e matéria seca total (MST)}

Essas características foram influenciadas significativamente pelas cultivares de soja, híbridos de sorgo, consórcio x monocultivo e também monocultivo do sorgo (Tabela1).

Entre as cultivares de soja, o maior destaque foi para a UFV-16 que proporcionou rendimento de 56.792 e $18.748 \mathrm{~kg} /$ ha, para massa verde e matéria seca total, respectivamente (Tabela 2). É interessante ressaltar que, apesar de ter levado em consideração o estádio em que a cultura da soja se encontrava $\left(R_{5}\right)$ para efetuar a prática do corte, todas as cultivares de soja e sorgo se encontravam no ponto ideal de colheita para forragem, havendo, dessa forma, um sincronismo no momento do corte. A única exceção foi para o híbrido CMSXS 756, que se encontrava em estádio avançado de maturação, pois esse híbrido comportou-se como o mais precoce na região onde foi montado o ensaio.

Dentre os híbridos de sorgo utilizados neste ensaio, o AG 2002 proporcionou o maior rendimento de massa verde e matéria seca total com rendimentos no consórcio de 64.683 e 20344 $\mathrm{kg} / \mathrm{h}$ ),respectivamente. Os híbridos AG 2006 e BR 601, de porte menor em relação ao AG 2002, não diferiram entre si e a pior performance foi constatada com o híbrido CMSXS 756. Devido ao seu baixo desenvolvimento, esse híbrido (Tabela 2) proporcionou maior desenvolvimento das cultivares de soja no consórcio, sendo esse fato considerado até certo ponto como vantajoso quando se trata de consórcio, pois se uma cultura não vai bem, a outra pode apresentar bom desempenho ocorrendo a complementação conforme relatam vários pesquisadores (ARAUJO, 1978; SILVA, 1980; CHAGAS et al., 1984; OLIVEIRA, 1989 e REZENDE, 1995).

Quando se compara os rendimentos médios do cultivo consorciado com os do monocultivo (Tabela 2), verifica-se uma superioridade do consórcio em relação ao monocultivo dos híbridos de sorgo na ordem de $(19.642 \mathrm{~kg} / \mathrm{ha}) 61,0 \%$ e $(4.971 \mathrm{~kg} / \mathrm{ha})$ $42,15 \%$ para massa verde e matéria seca total respectivamente. Todas as combinações consorciadas proporcionaram rendimentos numericamente superiores em relação ao monocultivo, exceto rendimento de massa seca para a combinação DOKO RC x AG 2002. A associação de maior destaque no consórcio foi obtida com UFV-16 x AG2002 que apresentou os maiores valores para essas características (72.792 e $23.555 \mathrm{~kg} / \mathrm{ha}$ ), sendo esses significativos quando comparados ao monocultivo do híbrido AG 2002. Devido ao maior desenvolvimento das cultivares de soja, quando estiveram consorciadas com o híbrido CMSXS 756, a associação dessas duas espécies proporcionou também rendimentos significativamente superiores no consórcio em relação ao monocultivo conforme se verifica através do teste ' $\mathrm{t}$ ' de contraste (Tabela 2). Em relação ao
monocultivo, da cultura matéria seca e proteína bruta total de sorgo + soja em dois cortes, em relação ao monocultivo de sorgo, obtidas no ensaio de avaliação de cultivares de sorgo e soja em consórcio e monocultivo, visando à produção de forragem, ano agrícola 1996/97, Lavras (MG).1999.

\begin{tabular}{lrrrr}
\hline & \multicolumn{3}{c}{ QUADRADOS MÉDIOS } \\
\cline { 2 - 5 } FV & GL & MASSA VERDE & MATÉRIA SECA & PROTEÍNA BRUTA \\
\hline ENTRE CONSÓRCIO & 15 & $414.136 .089,30^{*}$ & $36.587 .918,98^{*}$ & $363.157,84^{*}$ \\
SOJA & 3 & $247.782 .929,69^{*}$ & $22.560 .756,33^{*}$ & $714.620,16^{*}$ \\
SORGO & 3 & $1.717 .205 .846,35^{*}$ & $136.685 .795,51^{*}$ & $196.392,40^{\mathrm{ns}}$ \\
SOJA x SORGO & 9 & $35.230 .557,00^{\mathrm{ns}}$ & $7.897 .681,03^{\mathrm{ns}}$ & $301.592,22^{\mathrm{ns}}$ \\
ENTRE MONOCULTIVO & 3 & $1.304 .435 .329,86^{*}$ & $116.552 .966,63^{*}$ & $363.065,04^{\mathrm{ns}}$ \\
CONSÓRCIO x MONOC. & 1 & $3.703 .830 .027,00^{*}$ & $237.209 .757,30^{*}$ & $10.053 .357,65^{*}$ \\
ERRO MÉDIO & 36 & $69.716 .474,98$ & $6.870 .116,211$ & $179.539,52$ \\
\hline CV $(\%)$ & & 17,43 & 16,62 & 27,99 \\
\hline
\end{tabular}

* Significativo a $5 \%$ de probabilidade de erro; ns = não significativo. do sorgo, conforme podese observar na tabela 2 , o destaque, a semelhança do que ocorreu no consórcio, foi obtido também com o híbrido AG 2002, que apresentou rendimentos de 56.500 e $17.943 \mathrm{~kg} / \mathrm{ha}$ para massa 
Tabela 2 - Valores médios de massa verde (MVT), matéria seca (MST) e proteína bruta total (PBT) de sorgo e soja $(\mathrm{kg} / \mathrm{ha})$ obtidos no ensaio de avaliação de cultivares de sorgo e soja em consórcio e monocultivo, visando à produção de forragem, ano agrícola 1996/97, Lavras (MG).1999.

\begin{tabular}{lllc}
\hline TRATAMENTO & MVT (kg/ha) & MST (kg/ha) & PBT (kg/ha) \\
\hline CAC-1 x AG 2002 & $62.275^{\mathrm{NS}}$ & $21.911^{\mathrm{NS}}$ & $2.073^{*}$ \\
CAC-1 x AG 2006 & $45.917^{*}$ & $16.964^{\mathrm{NS}}$ & $1.501^{\mathrm{NS}}$ \\
CAC-1 x BR 601 & $48.708^{\mathrm{NS}}$ & $15.430^{\mathrm{NS}}$ & $1.397^{*}$ \\
CAC-1 x CMSXS 756 & $32.375^{*}$ & $10.910^{*}$ & $1.574^{*}$ \\
Doko RC x AG 2002 & $57.333^{\mathrm{NS}}$ & $16.599^{\mathrm{NS}}$ & $1.005^{\mathrm{NS}}$ \\
Doko RC x AG 2006 & $43.917^{\mathrm{NS}}$ & $17.226^{\mathrm{NS}}$ & $1.462^{\mathrm{NS}}$ \\
Doko RC x BR 601 & $55.292^{*}$ & $15.861^{\mathrm{NS}}$ & $1.454^{*}$ \\
Doko RC x CMSXS 756 & $38.333^{*}$ & $12.685^{*}$ & $2.002^{*}$ \\
UFV-16 x AG 2002 & $72.792^{*}$ & $23.555^{*}$ & $2.248^{*}$ \\
UFV-16 x AG 2006 & $54.417^{*}$ & $20.335^{*}$ & $2.333^{*}$ \\
UFV-16 x BR 601 & $60.917^{*}$ & $18.305^{*}$ & $1.671^{*}$ \\
UFV-16 x CMSXS 756 & $39.042^{*}$ & $12.796^{*}$ & $1.978^{*}$ \\
UFV-17 x AG 2002 & $66.333^{\mathrm{NS}}$ & $19.311^{\mathrm{NS}}$ & $1.583^{\mathrm{NS}}$ \\
UFV-17 x AG 2006 & $54.542^{*}$ & $16.117^{\mathrm{NS}}$ & $1.616^{\mathrm{NS}}$ \\
UFV-17 x BR 601 & $61.292^{*}$ & $17.700^{*}$ & $1.693^{*}$ \\
UFV-17 x CMSXS 756 & $35.958^{*}$ & $12.532^{*}$ & $1.910^{*}$ \\
\hline CAC-1 x SORGO & $47.319 \mathrm{~b}(1)$ & $16.304 \mathrm{ab}$ & $1.636 \mathrm{~b}$ \\
Doko RC x SORGO & $48.719 \mathrm{~b}$ & $15.593 \mathrm{~b}$ & $1.481 \mathrm{~b}$ \\
UFV-16 x SORGO & $56.792 \mathrm{a}$ & $18.748 \mathrm{a}$ & $2.058 \mathrm{a}$ \\
UFV-17 x SORGO & $54.531 \mathrm{ab}$ & $16.415 \mathrm{ab}$ & $1.700 \mathrm{ab}$ \\
\hline AG 2002 x SOJA & $64.683 \mathrm{a}$ & $20.344 \mathrm{a}$ & 1.727 \\
AG 2006 x SOJA & $49.698 \mathrm{~b}$ & $17.660 \mathrm{~b}$ & 1.728 \\
BR 601 x SOJA & $56.552 \mathrm{~b}$ & $16.824 \mathrm{~b}$ & 1.554 \\
CMSXS 756 x SOJA & $36.427 \mathrm{c}$ & $12.231 \mathrm{c}$ & 1.866 \\
\hline MÉDIA CONSÓRCIO & $51.840 \mathrm{~A}(2)$ & $16.765 \mathrm{~A}$ & $1.719^{\mathrm{A}}$ \\
\hline MONOCULTIVO & & & \\
AG 2002 & $56.500 \mathrm{a}$ & $17.943 \mathrm{a}$ & $1.021 \mathrm{a}$ \\
AG 2006 & $31.083 \mathrm{~b}$ & $13.871 \mathrm{~b}$ & $885 \mathrm{ab}$ \\
BR 601 & $35.500 \mathrm{~b}$ & $12.186 \mathrm{~b}$ & $649 \mathrm{~b}$ \\
CMSXS 756 & $5.708 \mathrm{c}$ & $3.176 \mathrm{c}$ & $227 \mathrm{c}$ \\
\hline MÉDIA MONOCULTIVO & $32.198 \mathrm{~B}$ & $11.794 \mathrm{~B}$ & $6955^{\mathrm{B}} \mathrm{B}$ \\
\hline & & & \\
\hline
\end{tabular}

* e NS - Contraste de 't'entre consórcio e monocultivo de sorgo, significativo a $5 \%$ e não significativo, respectivamente.

1. Médias seguidas pela mesma letra minúscula na coluna para cada característica isolada não diferem entre si pelo teste de Duncan a 5\% de probabilidade de erro.

2. Médias seguidas pela mesma letra maiúscula na coluna não diferem entre si pelo teste $\mathrm{F}$ a $5 \%$ de probabilidade de erro.

verde e matéria seca, respectivamente. Os híbridos AG 2006 e BR 601, como no consórcio, não diferiram entre si e o CMSXS 756 apresentou o pior rendimento $(5.708$ e $3.176 \mathrm{~kg} / \mathrm{ha})$. Nesse sistema de cultivo, os valores obtidos são superiores aos de CASELA et al. (1986), que obtiveram rendimentos que variaram de 36,0 a $41,7 \mathrm{t} /$ ha para a cultura do sorgo e similares aos obtidos por (LISEU, 1981; PEREIRA et al. 1993 e COSTA \& AZEVEDO, 1996).

\section{Rendimento de proteína bruta total}

Conforme pode-se verificar na tabela 1 , as cultivares de soja alteraram significativamente o rendimento de proteína bruta total. O destaque foi verificado para a cultivar UFV-16 que proporcionou rendimento de $2.058 \mathrm{~kg} / \mathrm{ha}$, e da UFV-17 com $1.700 \mathrm{~kg} / \mathrm{ha}$. Semelhante as características estudadas anteriormente, às cultivares de soja apresentaram o mesmo comportamento, sendo que a Doko RC e CAC-1 foram as de pior performance.

Por outro lado, não foi constatada diferença significativa entre os híbridos de sorgo, ocorrendo variação de $1.554 \mathrm{~kg} / \mathrm{ha}$, para o híbrido BR 601 a $1.866 \mathrm{~kg} / \mathrm{ha}$, para o híbrido CMSXS 756 (Tabelas 1 e 2). Devido ao menor porte desse último híbrido na região, o mesmo possibilitou maior rendimento das cultivares de soja, com maior teor de proteína bruta em sua forragem, quando comparado com a gramínea, justificando assim os altos valores encontrados no rendimento total de proteína bruta para condição de consórcio.

Em se tratando do consórcio, verifica-se, na média geral, que o seu rendimento foi aproximadamente $147 \% \quad(1.024 \mathrm{~kg} / \mathrm{ha})$ superior em relação ao monocultivo da gramínea conforme indica (Tabelas 1 e 2). É interessante observar que todas as combinações no consórcio superaram o monocultivo do sorgo, exceto a combinação DOKO RC x AG 2002 o que demostra a viabilidade da técnica. Somente as combinações das cultivares CAC-1, DOKO RC e UFV-17 consorciadas com AG-2006 e DOKO RC e UFV-17 com AG-2002 não apresentaram rendimentos que diferiram estatisticamente dos respectivos monocultivos de sorgo. Os maiores rendimentos foram obtidos com a cultivar UFV-16 consorciada com os híbridos AG 2006 e AG $2002(2.333 \mathrm{~kg} / \mathrm{ha}$ e $2.248 \mathrm{~kg} / \mathrm{ha}$, respectivamente). Os resultados obtidos concordam com os de vários autores que evidenciaram o efeito benéfico do consórcio gramínea $\mathrm{x}$ leguminosa na melhoria do valor nutritivo da forragem (CARNEIRO \& RODRIGUEZ, 1980; EVANGELISTA, 1986; SOOD \& SHARMA, 1992 e REZENDE, 1995).

Em condição de monocultivo, o destaque foi verificado novamente com o híbrido AG 2002 que proporcionou rendimento de $1.021 \mathrm{~kg} / \mathrm{ha}$, seguido do AG 2006 com $885 \mathrm{~kg} /$ ha (Tabela 2).

Dentre os vários objetivos a serem alcançados, nesse tipo de trabalho, a eleição do par das duas espécies de melhor desempenho constitui-se num dos objetivos principais. No presente trabalho, foi verificado um efeito significativo para todas características analisadas do fator consórcio versus monocultivo, demostrando mais uma vez a vantagem desse sistema sobre o monocultivo. Analisando 
as várias combinações obtidas, verifica-se que a associação sorgo-soja foi benéfica para todas características analisadas, tendo nesse sistema de cultivo, obtido os melhores resultados quando comparado ao monocultivo do sorgo. Dentre as várias combinações obtidas, o destaque é para a associação UFV-16 X AG 2002 que apresentou os maiores rendimentos para massa verde e matéria seca total e UFV $16 \mathrm{X}$ AG 2006 para proteína total.

\section{CONCLUSÕES}

O sistema consorciado proporcionou, em relação ao monocultivo, os maiores rendimentos de massa verde, matéria seca e proteína bruta total. Nesse sistema de cultivo, a combinação da cultivar UFV-16 com os híbridos AG 2002 e AG 2006 foram as de melhor performance.

Em consórcio e monocultivo, o híbrido AG 2002 foi o que mais se destacou para a produção de massa verde e matéria seca.

A associação soja sorgo constitui uma opção segura de fornecimento de forragem de qualidade aos animais.

\section{REFERÊNCIAS BIBLIOGRÁFICAS}

ARAÚJO, A.G.de. Sistemas culturais milho - feijão: Efeito de cultivares e populações de plantas de milho em três sistemas de consorciação. Viçosa-MG.78p. Dissertação (Mestrado em Fitotecnia) - Curso de Pós-graduação em Fitotecnia, Universidade Federal de Lavras, 1978.

CARDOSO, D.A.del.B. Maximização da exploração da soja [Glycine max (L.) Merrill]: Efeito do espaçamento, densidade e altura de corte na produção de feno e grãos da rebrota, cv. Cristalina. Lavras-MG, 1985. 83p. Dissertação (Mestrado em Fitotecnia) - Curso de Pós-graduação em Fitotecnia, Universidade Federal de Lavras, 1985.

CARNEIRO, A.M., RODRIGUEZ, N.M. Efeitos da consorciação de milho com leguminosas anuais na produção e qualidade de material para a ensilagem. Arquivos da Escola de Veterinária da UFMG, Belo Horizonte, v.30, n.2, p.219-227, 1978.

CARNEIRO, A.M., RODRIGUEZ, N.M. Influência da leguminosa na qualidade da silagem de milho. Arquivos da Escola de Veterinária da UFMG, Belo Horizonte, v.32, n.3, p.415-420, 1980

CASELA, C.R., BORGONOVI, R.A., SCHAFFERT, R.E. et al Cultivares de sorgo. Informe Agropecuário, Belo Horizonte, v.12, n.144, p.40-43, 1986.

CHAGAS, J.M., ARAÚJO, G.A.A., VIEIRA, C. O consórcio de culturas e razões de sua utilização. Informe Agropecuário, Belo Horizonte, v.10, n.118, p.10-12, 1984.

COMISSÃO DE FERTILIDADE DO SOLO DO ESTADO DE
MINAS GERAIS. Recomendações para o uso de corretivos e fertilizantes em Minas Gerais. $4^{\mathrm{a}}$ aproximação. Lavras, 1989. 159p.

COSTA, N.de L., AZEVEDO, D.M.P.de. Produção e composição química de cultivares de sorgo forrageiro. In: CONGRESSO NACIONAL DE MILHO E SORGO, 21, IAPAR, 1996, Londrina-PR. Resumos... Londrina : EMBRAPA, 1996. p.216.

EVANGELISTA, A.R. Consórcio milho-soja e sorgo-soja: rendimento forrageiro, qualidade e valor nutritivo das silagens. Viçosa-MG, 1986. 77p. Tese (Doutorado em Zootecnia) - Curso de Pós-graduação em Zootecnia, Universidade Federal de Viçosa, 1986.

FARIA, V.P.de. Técnicas de produção de silagens. In: SIMPÓSIO SOBRE MANEJO DE PASTAGENS, 8, 1986, Piracicaba-SP. Anais... Piracicaba : FEALQ, 1986. p.119-144.

FEHR, W.R.; CAVINESS, C.E. Stage of soybean development. Ames : Iowa State University, 1977. 12p. (Special Report, 80).

HARBERS, L.H., SHIRLEY, J.E., BOLSEN, K.K., et al. Evaluation of interseeded grain sorghum and soybean silage for mid-lactation dairy cows. Journal of Dairy Science, Champaign, v.75, p.204, 1992. (Supplement 1).

LIMA, J.A.de. Qualidade e valor nutritivo da silagem mista de capim-elefante (Pennisetum purpureum Schum) e soja (Glycine $\max$ L. Merrill), com e sem adição de farelo de trigo. Lavras-MG, 1992. 69p. Dissertação (Mestrado em Zootecnia) - Curso de Pós-graduação em Zootecnia, Universidade Federal de Lavras, 1992.

LISEU, L.C. Curva de produção, composição química, digestibilidade in vitro e taxa de fermentação do sorgo. Lavras-MG, 1981. 96p. Dissertação (Mestrado em Zootecnia) - Curso de Pós-graduação em Zootecnia, Universidade Federal de Lavras, 1981

MONTGOMERY, M.J. Soybeans-grain sorghum vs. corn for silage for lactating cows. Proceedings of the 38th Southern Pasture and Forage Crop Improvement Conference, 1982. In: Herbage Abstracts, v.53, n.10, p.490, Oct, 1983. (Abst. 4375).

OLIVEIRA, A.F.de. Efeito da associação de cultivares de milho (Zea mays L.) e soja (Glycine $\max ($ L.) Merrill) no rendimento e valor nutritivo da forragem. Lavras-MG, 1986. 74p. Dissertação (Mestrado em Fitotecnia) - Curso de Fitotecnia, Universidade Federal de Lavras, 1986.

OLIVEIRA, J.M.de. Rendimento, qualidade da forragem e valor nutritivo das silagens de sorgo (Sorghum bicolor $(L$.) Moench), forrageiro e granífero, consorciado com soja (Glycine max (L.) Merrill). Viçosa-MG, 1989. 57p. Tese (Doutorado em Zootecnia) - Curso de Pós-graduação em Zootecnia, Universidade Federal de Lavras, 1989.

PEREIRA, O.G., OBEID, J.A., GOMIDE, J.A., $\boldsymbol{e t} \boldsymbol{a l}$. Produtividade de uma variedade de milho (Zea mays L.) e de três variedades de sorgo (Sorghum bicolor (L.) Moench) e o valor nutritivo de suas silagens. Revista Ceres, Viçosa, v.22, n.1, p.31-38. jan./fev. 1993. 
REZENDE, P.M.de. Maximização da exploração da soja. I Efeito do corte aos 60 dias na produção de feno e grãos da rebrota. Pesquisa Agropecuária Brasileira, Brasília, v.19, n.3, p.329-336, mar.1984.

REZENDE, P.M.de. Capacidade competitiva de cultivares de milho e soja consorciados em função da produção de grãos e forragem. Lavras-MG, 1995. 154p. Tese (Doutorado em Fitotecnia) - Curso de Pós-graduação em Fitotecnia, Universidade Federal de Lavras, 1995.

REZENDE, P.M.de., TAKAHASHI, S. Maximização da exploração da soja [Glycine $\max ($ L.) Merrill]. IX. Efeito do sistema de cortes na seleção de cultivares para produção de feno. Ciência e Prática, Lavras, v.14, n.1. p.44-55, jan./abr.1990

SILVA, L.C.M.da. Cultivo consorciado de milho e soja. IPAGRO Informa, Porto Alegre, n.23, p.56-57, ago.1980.

SOOD, B.R., SHARMA, V.K. Effect of nitrogen level on the yield and quality of forage sorghum (Sorghum bicolor) intercropped with legumes. Indian Journal of Agronomy, New Delhi, v.37, n.4, p.642-644, dec, 1992.

Ciência Rural, v. 31, n. 3, 2001. 